\title{
Erratum to: Mass in failed renal allograft: Question
}

\author{
Molly Riemenschneider • John Makari • \\ Caroline Rochon • Fernando Ferrer • \\ Cynthia D'Alessandri-Silva
}

Published online: 7 October 2014

(C) IPNA 2014

\section{Erratum to: Pediatr Nephrol}

\section{DOI 10.1007/s00467-014-2928-y}

A mistake has occurred in the article on the first page, right column, fourth paragraph:

It should read: $8.2 \times 10^{3} / \mathrm{uL}$

The online version of the original article can be found at http://dx.doi.org/ 10.1007/s00467-014-2928-y.

M. Riemenschneider $(\bowtie) \cdot$ C. D'Alessandri-Silva

Department of Nephrology, Connecticut Children's Medical Center,

282 Washington Street, Hartford, CT 06106, USA

e-mail: mriemenschneider@connecticutchildrens.org

J. Makari · F. Ferrer

Department of Urology, Connecticut Children's Medical Center, 282

Washington Street, Hartford, CT 06106, USA

C. Rochon

Connecticut Children's Medical Center, 282 Washington Street,

Hartford, CT 06106, USA

C. Rochon

Transplant Program, Hartford Hospital, 80 Seymour Street, Hartford,

CT 06102, USA 